\title{
STUDIES OF GASTRIC PEPSIN. II. SECRETION OF PEPSIN IN CASES OF DUODENAL ULCER AND PSEUDO-ULCER
}

\author{
By FRANCES R. VANZANT, ${ }^{2}$ ARNOLD E. OSTERBERG; \\ WALTER C. ALVAREZ AND ANDREW B. RIVERS \\ (From the Section on Chemistry and the Division of Medicine, The Mayo Clinic, \\ Rochester, Minn.)
}

(Received for publication December 23, 1932)

Few articles on concentration of pepsin in the gastric juice of patients with disease of the stomach and duodenum are to be found in recent literature, and the results reported by different observers are not always in accord. We shall consider here only the concentration of pepsin in the gastric juice of persons suffering with the syndrome of peptic ulcer.

Wilcox (5), in 1908, reported that the concentration of pepsin in the gastric juice of persons with peptic ulcer and hyperacidity was usually higher, and never lower, than normal. Boas (1), in 1925, and HirschMamroth and Rindfleisch (3) likewise found that the concentration of pepsin was elevated in the presence of ulcer, provided blood was not present in the sample examined, but they quoted other workers who at times failed to find any increase. Polland and Bloomfield (4) reported that the range of concentration of pepsin was the same in patients with ulcer as in normal persons.

We have estimated the concentration of pepsin by a modification of the Gilman-Cowgill method (2), described in the preceding article (6). As an arbitrary standard of measurement a 1 per cent solution of Armour's $1: 10,000$ commercial pepsin was assumed to contain 1,000 units.

In the greater part of the investigation we examined gastric contents removed one hour after the ingestion of a test meal which consisted of eight arrowroot cookies and $400 \mathrm{cc}$. of water. We also determined the content of pepsin in the juice removed from the stomach in the morning, before breakfast. Although the same general conclusions may be drawn from studies of contents removed after a test meal and of juice from the fasting stomach, it is necessary to consider the results obtained with the two technics separately because of differences observed in the absolute values for pepsin.

\section{Duodenal ulcer}

The diagnosis of duodenal ulcer was made in 274 cases on the basis of the history and fluoroscopic examination. In fifty-seven cases the

\footnotetext{
${ }^{1}$ Fellow, Josiah Macy, Jr., Foundation, on duty at The Mayo Foundation, Rochester, Minnesota.
} 


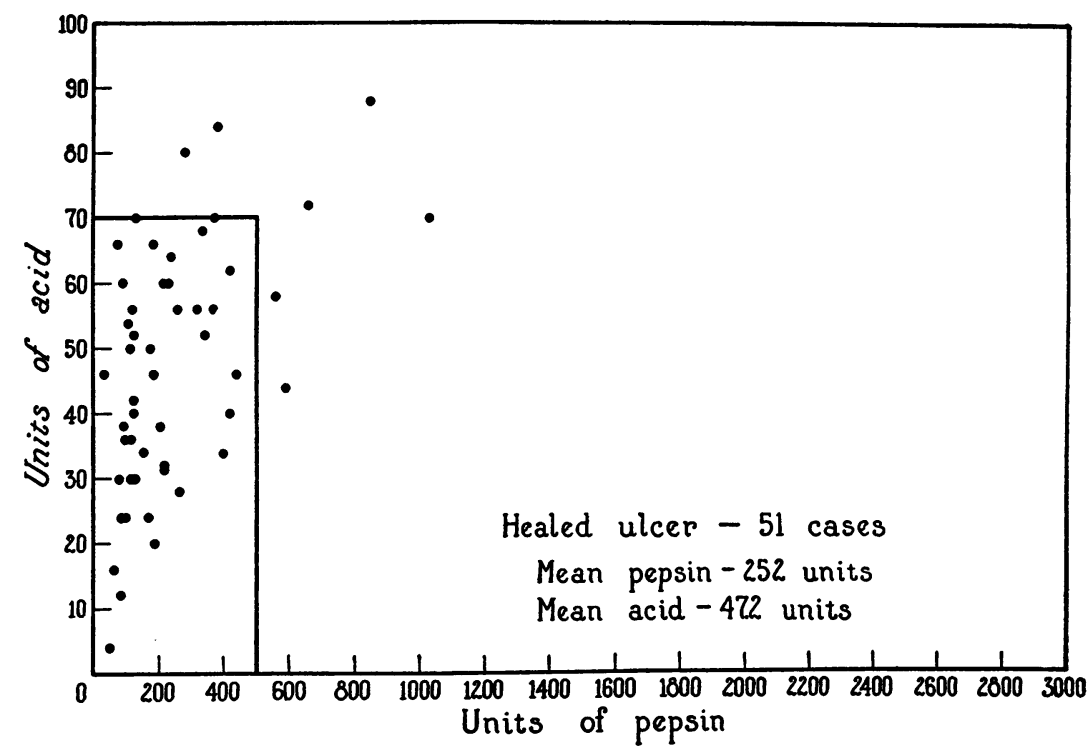

Fig. 1. The Distribution of Acid and Pepsin in Healed Duodenal Ulcer The bracket indicates limits of normal.

diagnosis was verified at operation. In fifty-one of the 274 cases a diagnosis of duodenal ulcer had been made; the duodenal cap was still deformed, - but symptoms of ulcer had not been present for a number of years. Most of the pepsin readings in these cases of presumably healed ulcer (Fig. 1) fell within normal limits, but the arithmetic mean was 252 units as compared with 145 units for the normal group (Table 1).

TABLE 1

Ewald test meal

\begin{tabular}{|c|c|c|c|c|c|}
\hline & \multirow{2}{*}{$\begin{array}{l}\text { Number } \\
\text { of cases }\end{array}$} & \multicolumn{2}{|c|}{$\begin{array}{c}\text { Pepsin in } \\
\text { units }\end{array}$} & \multicolumn{2}{|c|}{$\begin{array}{l}\text { Free acid in terms } \\
\text { of cc. of normal } \\
\text { sodium hydroxide }\end{array}$} \\
\hline & & Mean & $\begin{array}{l}\text { Standard } \\
\text { deviation }\end{array}$ & Mean & $\begin{array}{l}\text { Standard } \\
\text { deviation }\end{array}$ \\
\hline 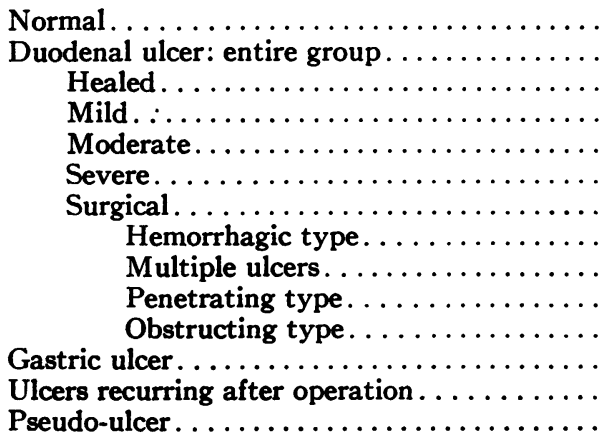 & $\begin{array}{r}85 \\
274 \\
51 \\
29 \\
92 \\
28 \\
77 \\
17 \\
15 \\
23 \\
11 \\
13 \\
18 \\
47\end{array}$ & $\begin{array}{l}145 \\
388 \\
252 \\
292 \\
332 \\
824 \\
423 \\
443 \\
398 \\
407 \\
198 \\
230 \\
476 \\
467\end{array}$ & $\begin{array}{l}125 \\
343 \\
209 \\
334 \\
312 \\
505 \\
300 \\
272 \\
273 \\
238 \\
116 \\
173 \\
341 \\
384\end{array}$ & \begin{tabular}{|l|}
34.2 \\
55.5 \\
47.2 \\
54.9 \\
55.3 \\
62.2 \\
58.9 \\
63.8 \\
61.1 \\
62.1 \\
51.1 \\
46.3 \\
55.2 \\
49.6
\end{tabular} & $\begin{array}{l}12.8 \\
18.0 \\
18.8 \\
18.3 \\
16.2 \\
17.2 \\
17.0 \\
14.2 \\
15.8 \\
16.4 \\
14.2 \\
19.6 \\
20.8 \\
18.0\end{array}$ \\
\hline
\end{tabular}


In the remaining 223 cases the patients complained of active symptoms of duodenal ulcer. The mean value for pepsin presented by these patients was 419 units, which is approximately two and five-tenths times the mean value for normal persons. The readings for pepsin in many cases fell far outside the normal limits.

We next looked to see if there might be a difference between the average concentration of pepsin in cases of mild and severe ulcer. The difficulty, of course, was to find satisfactory criteria for division of the cases into groups. We finally decided to classify the cases according to the treatment which was required. We classified as mild those cases in which the symptoms were so trivial and so easily controlled that no treatment of any kind was indicated, and as moderately severe that large group in which medical treatment gave relief. The mean value for pepsin in the group with mild symptoms was 292 units, only slightly higher than that found among patients with healed ulcer; in the group of patients with more serious trouble it was 332 units (Fig. 2).

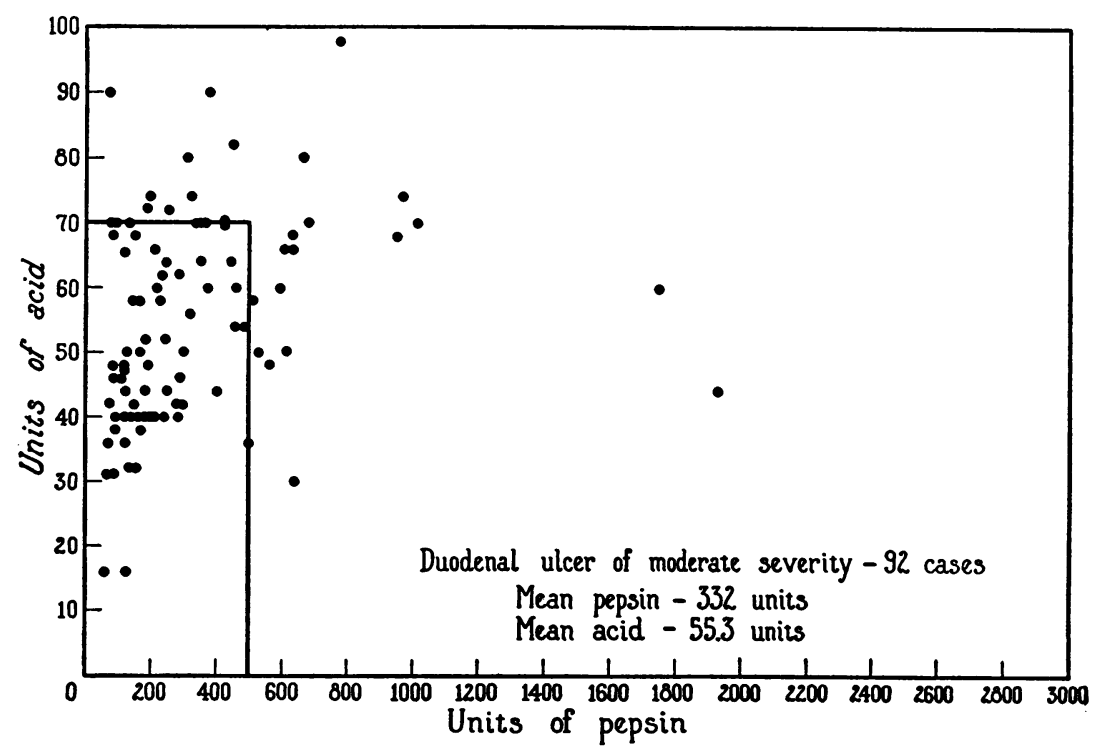

Fig. 2. The Distribution of Acid and Pepsin in Duodenal Ulcer of Moderate Severity

The bracket indicates limits of normal.

We considered as severe those cases in which symptoms persisted in spite of the most careful treatment in the hospital. Almost all of the values for pepsin in this group fell outside the limits of normal (Fig. 3), and in many instances very high readings were obtained. The mean value was 824 units, more than two and five-tenths times that seen in the ordinary case of duodenal ulcer, and nearly six times that seen in normal 
persons. In this group we did not include cases in which there was hemorrhage or a tendency to perforation because such complications usually constituted indications for surgical treatment. We did include many of those cases in which the patient was of a tense, nervous, "go-getter"

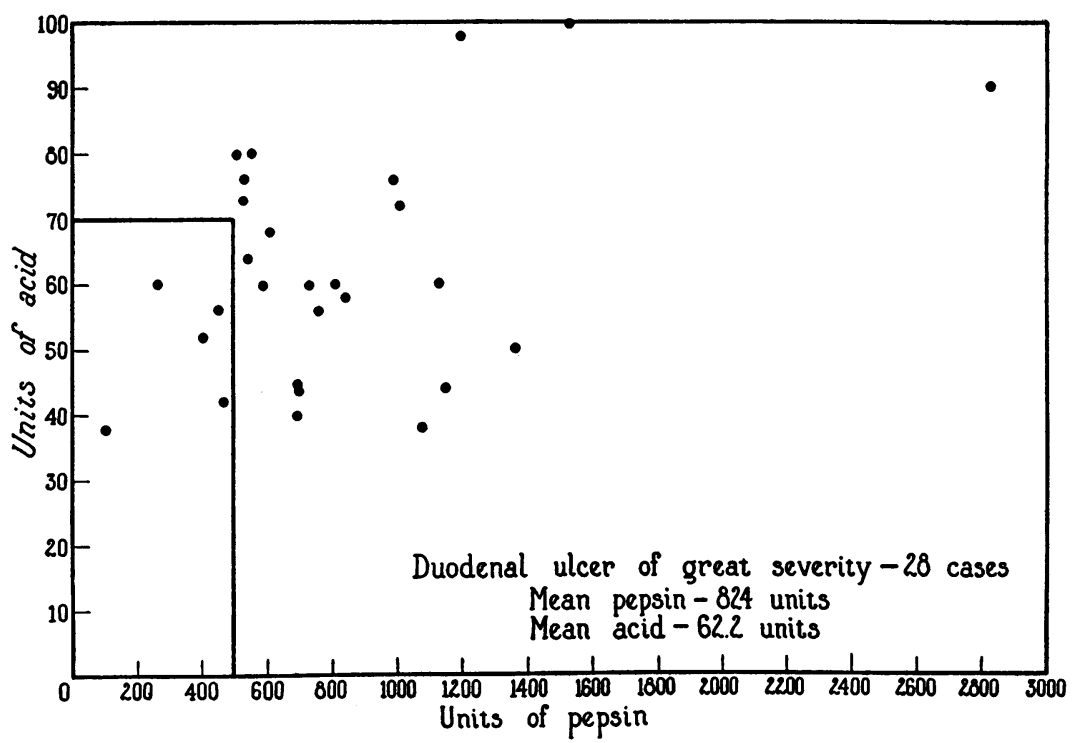

Fig. 3. The Distribution of Acid and Pepsin in Severe Duodenal Ulcer The bracket indicates limits of normal.

type; the sort of patient whom gastro-enterologists and gastric surgeons have come to recognize as a poor subject for either medical or surgical treatment. It was in this type of case that the highest readings were obtained.

Seventy-seven patients were advised to submit to surgical treatment either because of the presence of some complication or because of the chronicity or intractability of the disease. In this group the average value for pepsin was 423 units, or about 100 units higher than the average for the medically treated patients.

On analyzing the surgical cases we found a hemorrhagic type of ulcer in seventeen, multiple ulcers in fifteen, and penetrating ulcers in twentythree cases. In these three groups the values for pepsin were somewhat higher than among patients who had a less serious form of the disease. The mean for bleeding ulcers was $\mathbf{4 4 3}$ units; for multiple ulcers it was 398 units, and for penetrating ulcers it was $\mathbf{4 0 7}$ units. Among the group of patients treated surgically there were eleven with some cicatricial obstruction at the pylorus. In most of these cases the ulcer was chronic; in some it appeared to be healed. In the cases in which there was moderate 
obstruction the mean value for pepsin was even lower than in the group of patients classed as having healed ulcers; namely, 198 units. It should be noted here that all cases of ulcer in which there was gross retention of gastric contents were excluded from this study. This was to avoid the complication of marked dilution of the gastric juice.

Fasting juice. We estimated the concentration of pepsin in the fasting juice of forty patients with duodenal ulcer. They were divided into two groups: first, those with mild, and second, those with intractable, ulcer. It was found that the twenty-four who responded readily to treatment had an average value for pepsin of 537 units, as compared with 388 units for normal persons; those with severe symptoms had an average of 1,592 units (Table 2). It is evident that the pepsin in the fasting juice

TABLE 2

Fasting juice

\begin{tabular}{|c|c|c|c|c|c|c|}
\hline \multirow{2}{*}{ Diagnosis } & \multirow{2}{*}{ Male } & \multirow{2}{*}{ Female } & \multicolumn{2}{|c|}{ Pepsin, units } & \multicolumn{2}{|c|}{ Free $\mathrm{HCl}^{*}$} \\
\hline & & & Mean & $\begin{array}{l}\text { Standard } \\
\text { deviation }\end{array}$ & Mean & $\begin{array}{l}\text { Standard } \\
\text { deviation }\end{array}$ \\
\hline $\begin{array}{l}\text { Normal } \ldots \ldots \ldots \ldots \ldots \ldots \\
\text { Moderately severe ulcer } \ldots \ldots \ldots \ldots \ldots \ldots \\
\text { Severe ulcer } \ldots \ldots \ldots \ldots \ldots \ldots \ldots \ldots \ldots\end{array}$ & $\begin{array}{l}13 \\
18 \\
16\end{array}$ & $\begin{array}{r}11 \\
6\end{array}$ & $\begin{array}{r}388 \\
537 \\
1592\end{array}$ & $\begin{array}{r}524 \\
617 \\
1020\end{array}$ & $\begin{array}{l}13 \\
27 \\
43\end{array}$ & $\begin{array}{l}19 \\
24 \\
23\end{array}$ \\
\hline
\end{tabular}

* In terms of cc. of normal sodium hydroxide per liter.

with the different types of ulcer varies in the same way that it does in the juice after a test meal, except that the actual values are higher and the individual variation is greater.

\section{Pseudo-ulcer}

A study was made of values for pepsin in a group of forty-seven patients who had symptoms sufficiently suggestive of ulcer to justify gastric analysis and fluoroscopic examination of the stomach. In every case the presence of atypical features in the history and the inability of the roentgenologist to detect any deformity in the stomach or cap caused the clinicians to make a diagnosis of pseudo-ulcer. The spot diagram (Fig. 4) shows that the distribution of values for pepsin is similar to that in cases of ulcer and that some figures are so high as to resemble closely those found in the presence of the most intractable ulcer.

In many of the cases there was close correlation between the concentration of pepsin in the stomach and the severity of the symptoms. Just as in the case of patients with actual ulcer, there was striking correlation between the amount of pepsin and the degree of tenseness and nervous activity shown by the individual. 
In six cases in which the diagnosis of pseudo-ulcer was confirmed by the inability of the surgeon at the time of operation to find an ulcer, determinations of pepsin made on fasting juice disclosed an average value of 880 units as compared to the normal mean fasting value of 388 units.

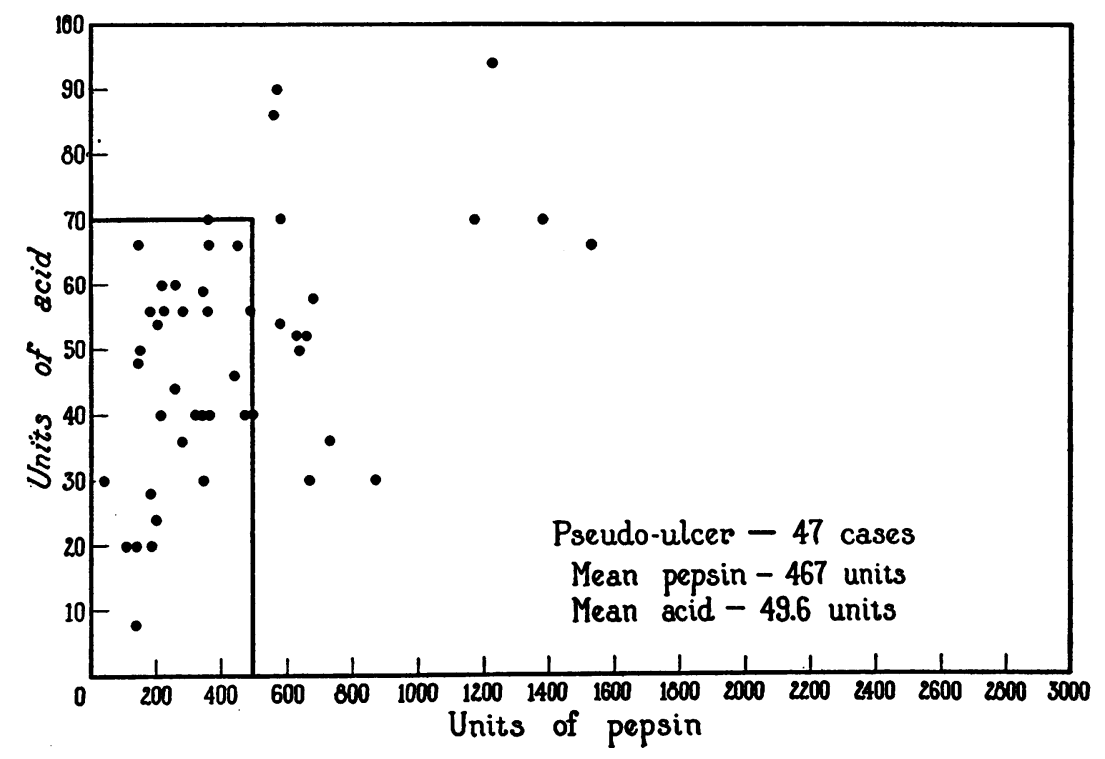

Fig. 4. Distribution of Acid and Pepsin in Pseudo-Ulcer

The bracket indicates limits of normal.

\section{Gastric ulcer}

The diagnosis of gastric ulcer was made in thirteen cases on the basis of roentgenologic examination or surgical exploration. The mean value for pepsin was 230 units, which is slightly higher than normal.

\section{Recurrent and gastrojejunal ulcers}

There were eighteen patients who, after an operation for relief of peptic ulcer, returned with a new ulcer, either in the duodenum or at the stoma made by gastro-enterostomy. The mean value for pepsin was 476 units. This figure is about one-third higher than that found by us in examination of patients with duodenal ulcer for whom operation was advised. The fact that in many of these cases the gastric juice was diluted by intestinal juice regurgitating through the gastro-enteric stoma makes it seem probable that the secretion of pepsin was even greater than the figures would indicate. It is of interest that the remaining part of the stomach of one of these patients who had undergone extensive gastric resection secreted enough pepsin to push the concentration up to 850 units. 


\section{The study of pepsin is of more clinical value than the study of acid}

We were led to a study of gastric pepsin by the fact that measurement of acid has so far been of so little decisive clinical value. The question now is: Will the differences which we have found in the secretion of pepsin in different diseases be of any more value than are the measurements of acidity? Several of the early workers felt that there is such a high degree of correlation between the acid and the ferment that little advantage can be gained from determining pepsin except in those cases in which it is desirable to distinguish between achlorhydria and true achylia. Our observations lead us to disagree with this view. Although it is true that high concentrations of pepsin are commonly associated with hyperacidity, and low concentrations with hypoacidity, the rule is by no means invariable, as the coefficients in Table 3 show.

TABLE 3

Relation between concentration of pepsin and free hydrochloric acid in gastric juice

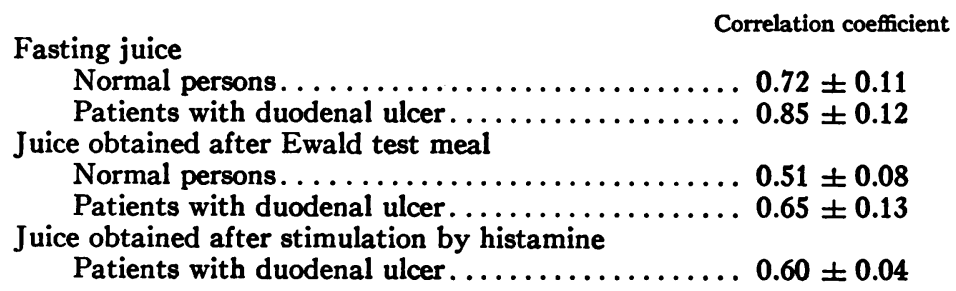

The fact that these coefficients are far from unity shows that often the acid titer and the amount of pepsin do not vary in the same way or to the same degree. When this happens the way is left open for the possibility that a study of the pepsin, another constituent of the gastric juice, will give information of clinical value which was not supplied by titration of the acid alone.

A glance at Figure 5 reveals that although there are definite differences between the mean acidity of normal persons and that of patients with mild and with severe ulcer, the distributions overlap so closely that in only a few cases will the physician be able to prophesy, from the gastric acidity alone, which ulcers will be hard to treat. On turning now to the curves representing values of pepsin in the three groups of cases, one sees that there is less overlapping of the distributions and when one obtains a reading higher than 800 or 900 units in a case of ulcer, one can be almost certain that the ulcer will be difficult to cure. Unfortunately it is not possible with the help of determinations of pepsin to distinguish patients with pseudo-ulcer from those with real ulcer.

It should be noted, also, that whereas it is almost impossible for anyone to have a free acid titer more than twice the normal average, 


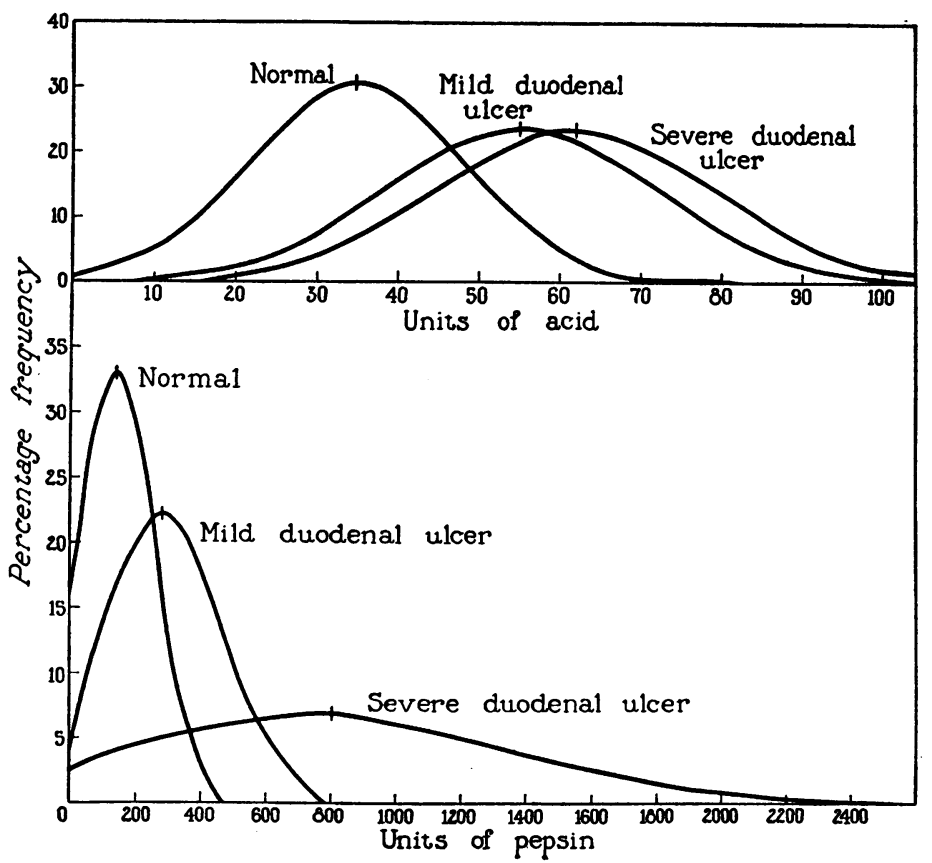

Fig. 5. Distribution of Pepsin and Acid in Normal Persons and in Patients with Mild and Severe Ulcer

readings for pepsin occur from fifteen to twenty times the normal average. It is this widening of the distribution of the measurements made in cases of disease, a widening that carries so many of the figures beyond the possible range of normal, which makes us hopeful that the test will have decided value in clinical practice.

\section{SUMMARY}

Values for pepsin are usually increased in the presence of peptic ulcer, and there is a high degree of correlation between the amount of the ferment and the severity and intractability of the symptoms. Unfortunately the determination cannot be used to prove the presence of ulcer because very high values for pepsin are commonly found in cases in which patients are tense and nervous, and present a syndrome resembling that of ulcer. Its main value, therefore, seems to be in estimating the prognosis in cases of known ulcer.

\section{BIBLIOGRAPHY}

1. Boas, I., Deutsche med. Wchnschr., 1925, 1, 511. Eine neue Methode der Pepsinbestimmung im Mageninhalt.

2. Gilman, Alfred and Cowgill, G. R., J. Biol. Chem., 1930, 1xxxviii, 743. The Determination of Peptic Activity: an Examination and Application of the Gates Method of Proteolytic Enzyme Titration. 
3. Hirsch-Mamroth, Paul and Rindfleisch, Hermann, Deutsche med. Wchnschr., 1925, 1, 512. Ergebnisse der Magensaftuntersuchung mit der neuen Pepsinbestimmung nach Boas.

4. Polland, W. S., and Bloomfield, A. L., J. Clin. Invest., 1930, ix, 107. The Diagnostic Value of Determinations of Pepsin in Gastric Juice.

5. Wilcox, W. H., Lancet, 1908, ii, 220. The Importance and Significance of the Chemical Examination of the Gastric Contents after a Test Meal with a New Method for Estimating the Ferment Activity of the Gastric Contents.

6. Osterberg, A. E., Vanzant, F. R. and Alvarez, W. C., J. Clin. Invest., 1933, xii, 551. Studies of Gastric Pepsin. I. Methods of Measurement and Factors which Influence It. 